\title{
Vital Sign and Location/Attitude Monitoring with Sensor Networks for the Proposed Rescue System for Disabled and Elderly Persons Who Need a Help in Evacuation from Disaster Areas
}

\author{
Kohei Arai ${ }^{1}$ \\ Graduate School of Science and Engineering \\ Saga University \\ Saga City, Japan
}

\begin{abstract}
Method and system for vital sign (Body temperature, blood pressure, bless, Heart beat pulse rate, and consciousness) and location/attitude monitoring with sensor network for the proposed rescue system for disabled and elderly persons who need a help in evacuation from disaster areas is proposed. Experimental results show that all of vital signs as well as location and attitude of the disabled and elderly persons are monitored with the proposed sensor networks.
\end{abstract}

Keyword—vital sign; heart beat puls ratee; body temperature; blood pressure; blesses; consciousnes; seonsor network

\section{INTRODUCTION}

Handicapped, disabled, diseased, elderly persons as well as peoples who need help in their ordinary life are facing too dangerous situation in event of evacuation when disaster occurs. In order to mitigate victims, evacuation system has to be created. Authors proposed such evacuation system as a prototype system already [1]-[4]. The system needs information of victims' locations, physical and psychological status as well as their attitudes. Authors proposed sensor network system which consist GPS receiver, attitude sensor, physical health monitoring sensors which allows wearable body temperature, heart beat pulse rates; bless monitoring together with blood pressure monitoring [5]-[7]. Also the number of steps, calorie consumptions is available to monitor. Because it is difficult to monitor the blood pressure with wearable sensors, it is done by using the number of steps and body temperature. In addition to these, psychological status is highly required for vital sign monitoring (consciousness monitoring). By using EEG sensors, it is possible to monitor psychological status in the wearable sensor. These are components of the proposed physical health and psychological monitoring system.

Method and system for vital sign (Body temperature, blood pressure, bless, Heart beat pulse rate, and consciousness) and location/attitude monitoring with sensor network for the proposed rescue system for disabled and elderly persons who need a help in evacuation from disaster areas is proposed. Experimental results show that all of vital signs as well as location and attitude of the disabled and elderly persons are monitored with the proposed sensor networks.
Section 2 describes the proposed acceleration sensor system followed by experiment method and results. Then conclusion is described together with some discussions..

\section{PROPOSED SENSOR NETWORK SySteM}

\section{A. System Configuration}

Figure 1 shows the entire system configuration of the proposed physical and psychological health monitoring system. Patients have physical and psychological health sensors and send the acquired data through Bluetooth and Internet to the Health Data Collection Center: HDCC server. On the other hand, volunteers receive health data of the previously designated several patients together with traffic flow information and appropriate route information. When something wrong occurs on the designated patients, HDCC provides information which required for rescue to the designated volunteers then the volunteers rescue patients in an efficient and an effective manner.

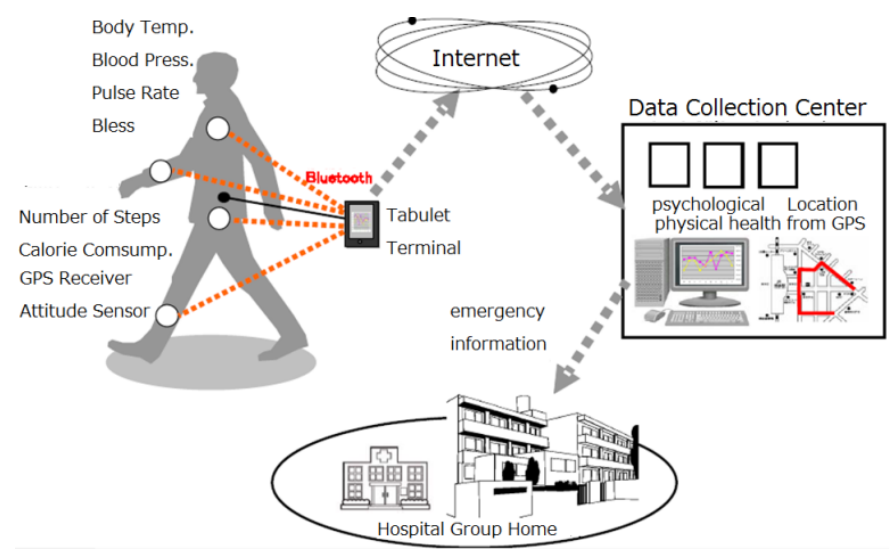

Fig. 1. Entire system configuration of the proposed wearable physical and psychological health monitoring system

\section{B. Sensor and Communication Ssystem}

In order for evacuation and rescue, victims' location and attitude is important. Therefore, GPS receiver and accelerometer are added to the aforementioned measuring 
sensors for body temperature pulse rate, blood pressure, bless, and eeg, emg. All sensors should be wearable and can be attached to ones' tall forehead. Acquired data can be transmitted to mobile devices in ones' pockets. Through WiFi network or wireless LAN connection, acquired data can be collected in the designated information collection center. Then acquired data can be refereed from the designated volunteers who are responsible to help victims for evacuation and rescue.

\section{EXPERIMENTS}

\section{A. Experimental Method}

Four patients are participated to the experiments. The difference due to gender can be discussed through a comparison between patients $\mathrm{A}$ and $\mathrm{C}$ while the difference due to age can be discussed through a comparison between patients B and C. Meanwhile, the difference due to the degree of Alzheimer can be discussed through a comparison between patients B and D as shown in Table 1.

TABLE I. FOUR PATIENTS

\begin{tabular}{|l|l|r|l|}
\hline Patient & Male/Female & Age & Remarks \\
\hline 1 & Male & 37 & Good in Health \\
\hline 2 & Female & 47 & Good in Health \\
\hline 3 & Female & 39 & Good in Health \\
\hline 4 & Female & 91 & Weak Alzheimer \\
\hline 5 & Male & 36 & Good in Health \\
\hline 6 & Male & 39 & Good in Health \\
\hline 7 & Male & 49 & Good in Health \\
\hline 8 & Female & 29 & Good in Health \\
\hline 9 & Female & 53 & Good in Health \\
\hline 10 & Female & 56 & Good in Health \\
\hline 11 & Female & 58 & Good in Health \\
\hline
\end{tabular}

Experiments are conducted for eight hours a day for almost every working day (Monday to Friday) for six months starting from May 2012. Measuring time intervals are different by the measuring items. GPS location can be measured every two seconds while accelerometer data can be obtained every 10 seconds.

Meanwhile, body temperature, pulse rate can be measured every one minutes while blood pressure is measured every one hour together with EEG and EMG signals. The number of steps is measured when the walking event happened. At the end of day, four patients evaluate their physical and psychological conditions which are listed in Table 2.

The 20 items listed in the Table 2 are questionnaires for four patients. In the Table, $\mathrm{Ai}$ is questionnaire for physical health while $\mathrm{Bi}$ is questionnaire for psychological health. The patients respond to the questionnaire above with five levels range from 0 to 4 grades. Total Score is defined as sum of the aforementioned self evaluation of 20 items including physical and psychological health items.
TABLE II. SElF EVALUATION ITEMS

\begin{tabular}{|l|l|}
\hline A1 & Feel fever \\
\hline B1 & Loosing thinking capability \\
\hline A2 & Feel tiredness \\
\hline B2 & Could not sleep well \\
\hline A3 & Get tired after exercise \\
\hline B3 & Feel bad \\
\hline A4 & Muscle hurt \\
\hline B4 & Unconfident about health \\
\hline A5 & Feel depression \\
\hline B5 & Do not want to work \\
\hline A6 & Limper hurt \\
\hline B6 & Cannot remember something \\
\hline A7 & Head ach \\
\hline B7 & Loosing balance \\
\hline A8 & Cannot recover after sleep \\
\hline B8 & Cannot think deeply \\
\hline A9 & Throat hurt \\
\hline B9 & Loosing concentration \\
\hline A10 & Joint hurt \\
\hline B10 & Sleep for too long time \\
\hline
\end{tabular}

\section{B. Experimental Results}

Figure 2 shows physical and psychological stress for the patients. Physical and psychological stress is different each other participants as shown in Figure 2.There are patients who are sensitive to their stress such as Patient No.8. There are also patients who are not so sensitive to their stress such as patient No. 5.

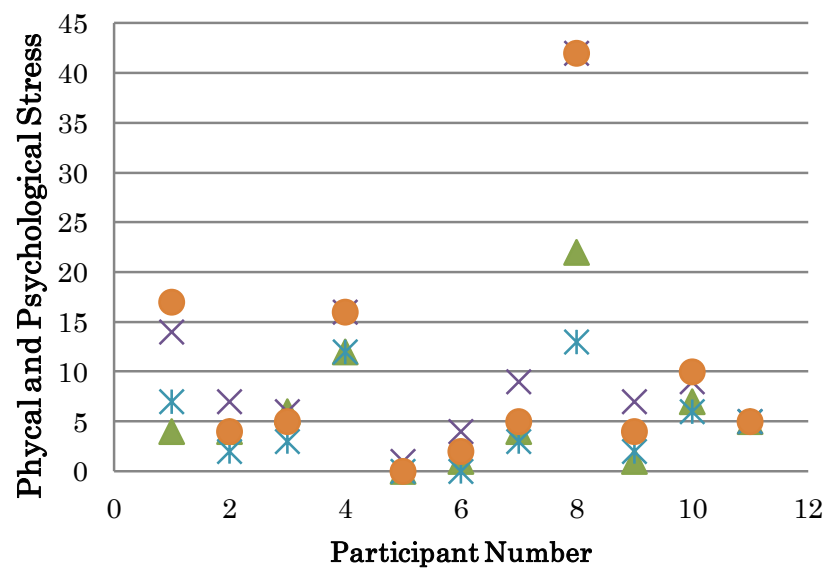

Fig. 2. Physical and psychological stress for the patients

Physical and psychological stress does not depend on male / female difference as shown in Figure 3. Also it is found that physical and psychological stress does not depend on age as shown in Figure 4 (a). Also Figure 4 (b) shows age dependency on physical conditions of body temperature, blood pressure, pulse rate, and the number of steps. 
An example of relation between total score of stress (sum of physical and psychological stress) and measured physical conditions of body temperature, blood pressure, pulse rate, and the number of steps (for the patient with weak Alzheimer) is shown in Figure 5.

As shown in Figure 5, there is no relation between total score of stress (sum of physical and psychological stress) and measured physical conditions of body temperature, blood pressure, pulse rate, and the number of steps (for the patient with weak Alzheimer). This is same thing for the other patients. During the experiments, patients have to repeat the following cycle of "walk for 10 minutes and then take a rest for 10 minutes" for 10 times. Therefore, only the number of steps is proportional to the total score.

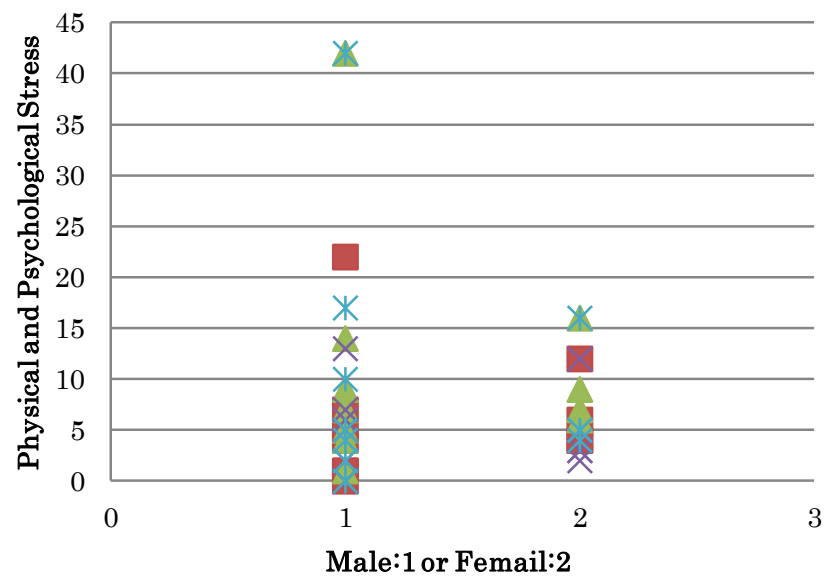

Fig. 3. Sex independency on phycal and psychological stress

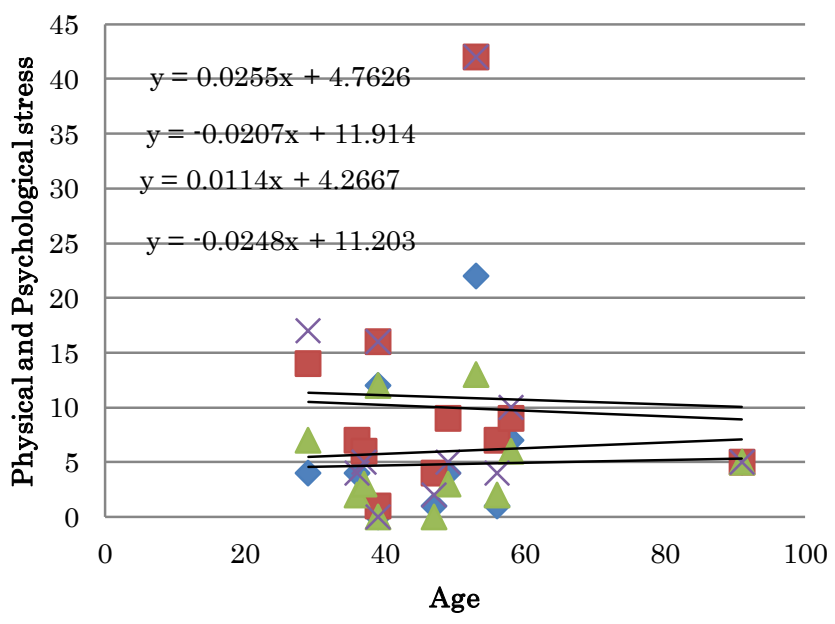

(a) Age independency on physical and psychological stress

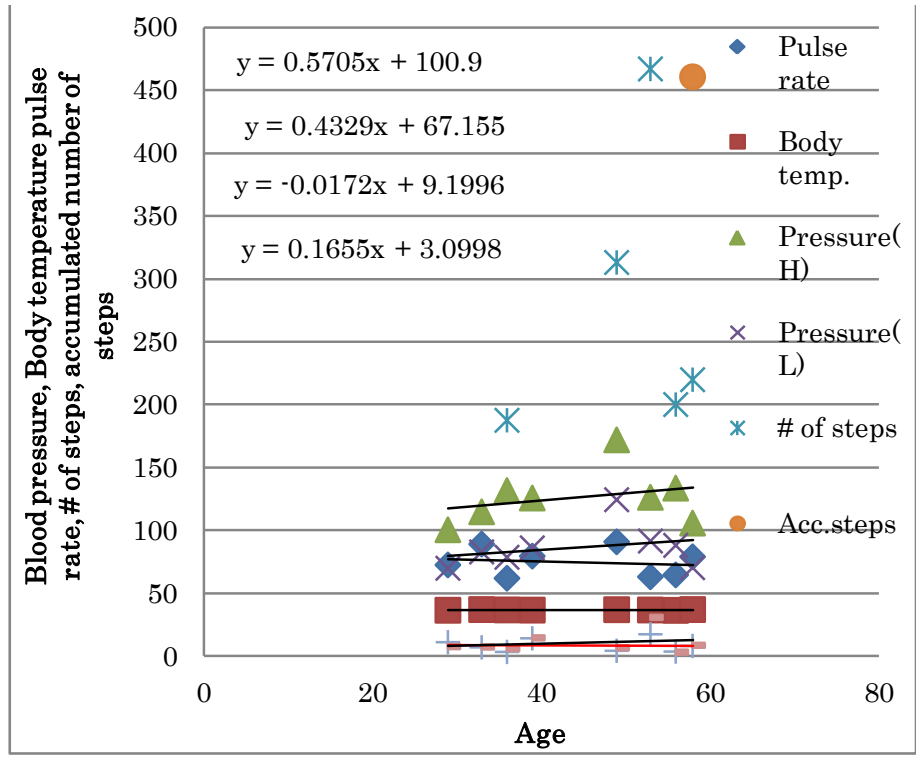

(b) Relation between physical conditions and age

Fig. 4. Age independency on physical and psychological stress as well as age dependency on physical conditions

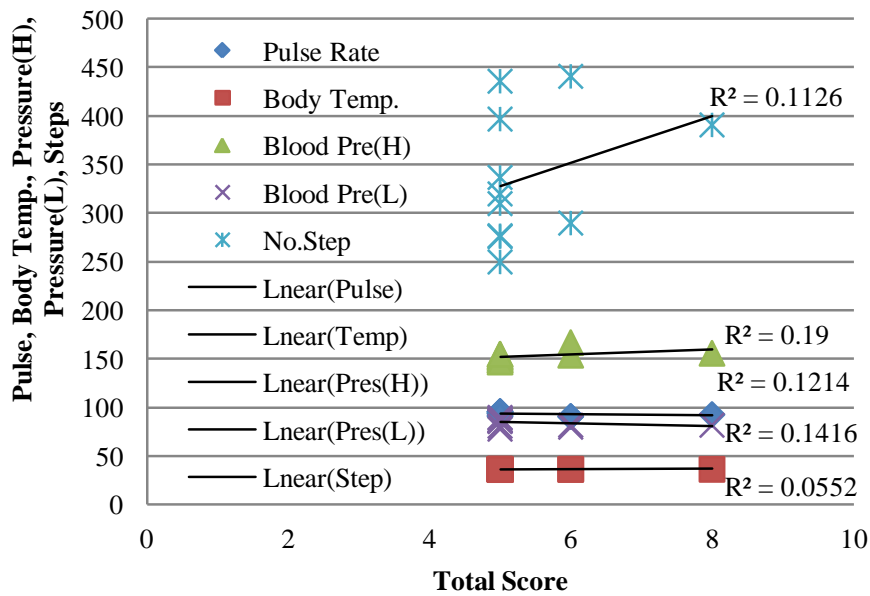

Fig. 5. An example of relation between total score of stress (sum of physical and psychological stress) and measured physical conditions of body temperature, blood pressure, pulse rate, and the number of steps (for the patient with weak Alzheimer)

In accordance with increasing of time duration, the number of steps is increased obviously. In accordance with increasing of the number of steps, blood pressure (High) and blood pressure (Low) is increased usually. It, however, is not always that pulse rate is proportional to the number of steps as shown in Figure 6. 


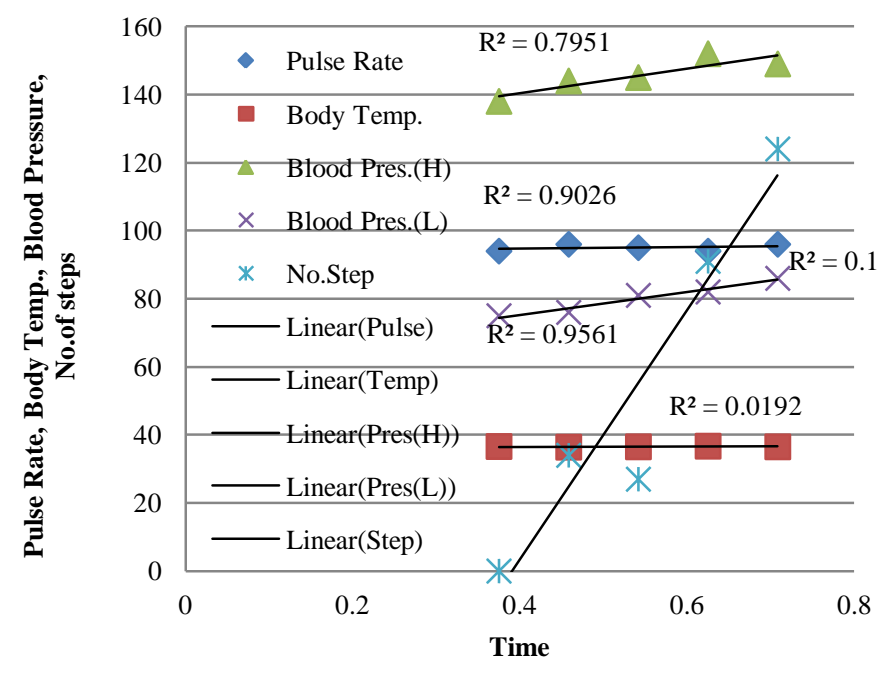

(a)Patient with weak Alzheimer (Minimum total score)

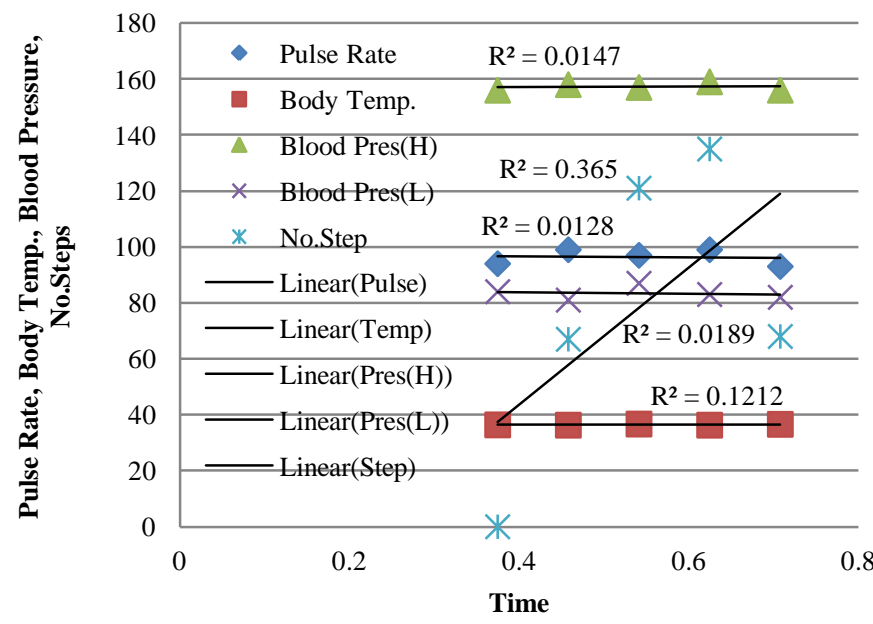

(b)Patient with weak Alzheimer (Maximum total score)

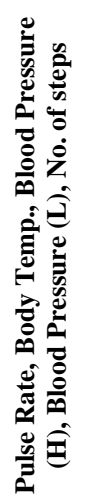

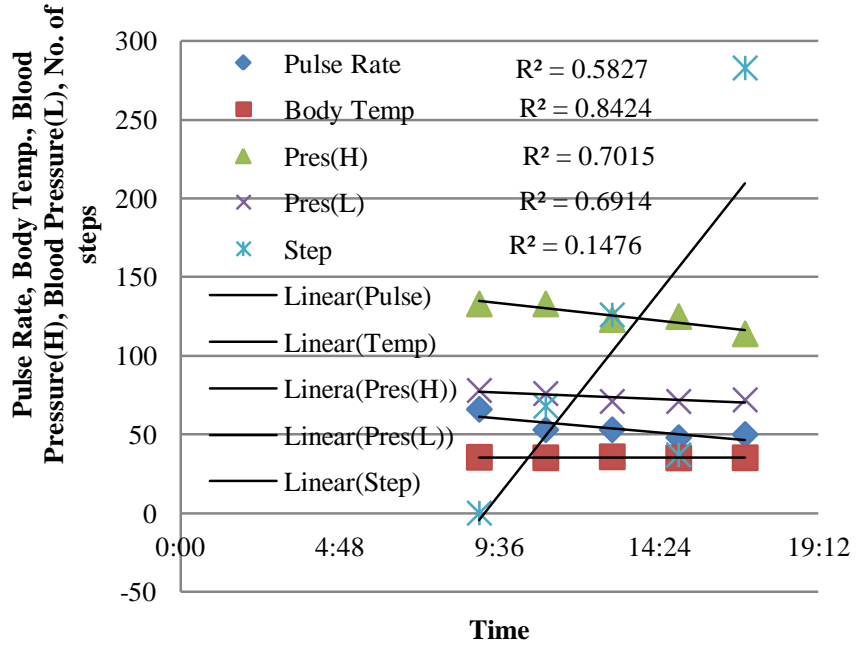

(d) Male patient whose age is 37 (Maximum total score)

Fig. 6. Examples of relation between the number of steps (Time) and measured physical conditions, blood pressure, pulse rate, body temperature

In more detail, relation between physical stress as well as psychological stress and measured physical conditions of blood pressure, pulse rate, body temperature and the number of steps are shown in Figure 7 together with relation between standard deviation of measured physical conditions of blood pressure, pulse rate, body temperature and the number of steps and physical and psychological stress. Figure 8-13 shows relations between physical stress as well as psychological stress and measured physical conditions of blood pressure, pulse rate, body temperature and the number of steps together with relation between standard deviation of measured physical conditions of blood pressure, pulse rate, body temperature and the number of steps and physical and psychological stress for the male whose age is 49 years old, the female whose age is 58 years old, the female whose age is 56 years old, the male whose age is 39 years old, the female whose age is 53 years old, the female whose age is 29 years old, respectively.

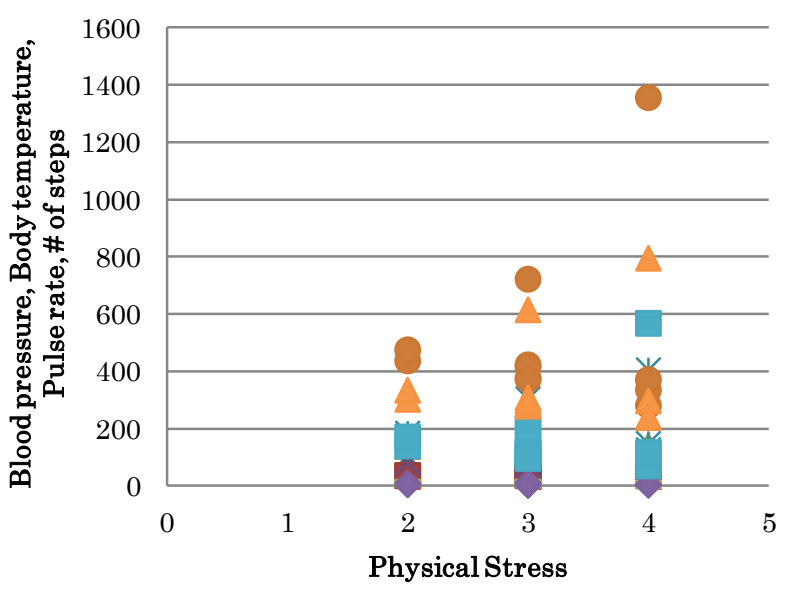

(a)Mean of physical condition (Physical stress)

(c)Male patient whose age is 37 (Minimum total score) 


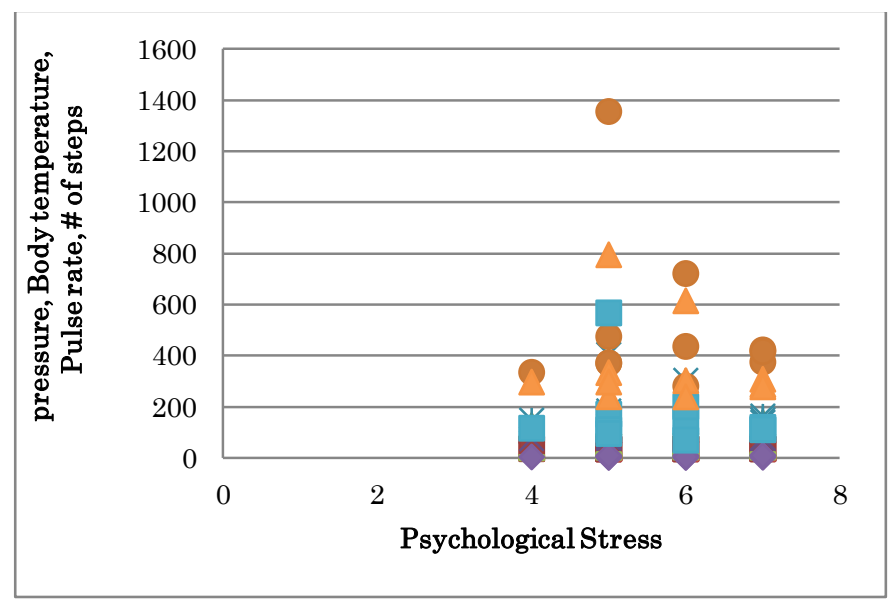

(b) Mean of physical condition (Psychological stress)

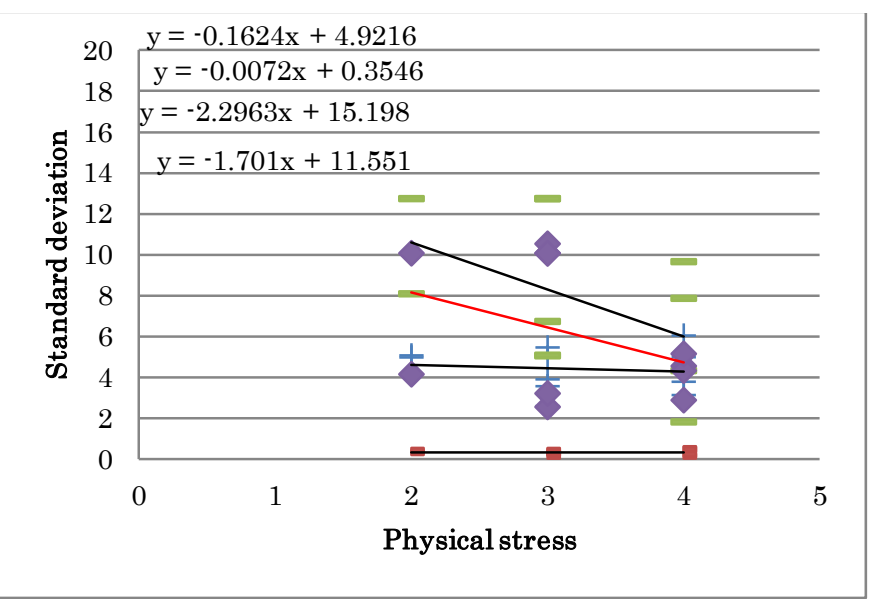

(c) Standard deviation of physical condition (Physical stress)

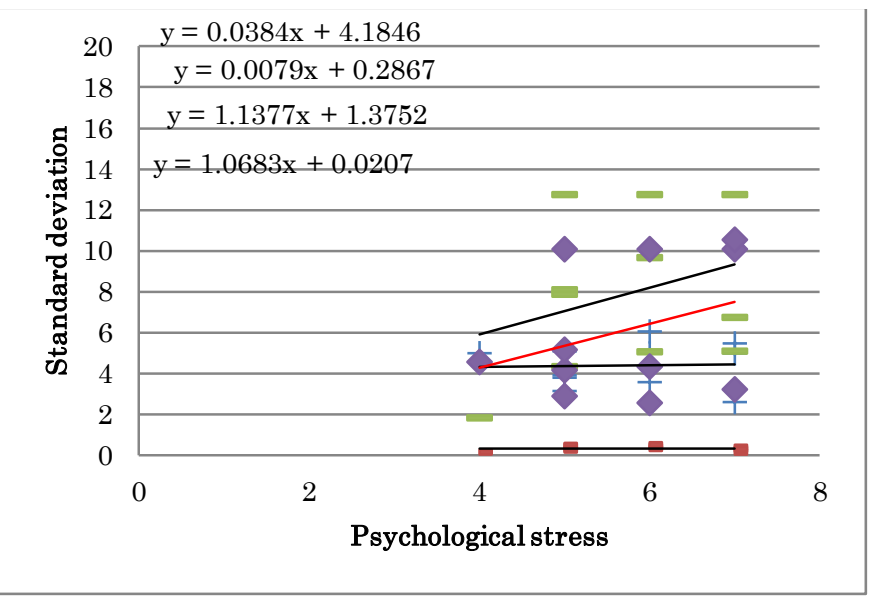

(d)Standard deviation of physical condition (Psychological stress)

Fig. 7. Relation between physical stress as well as psychological stress and measured physical conditions of blood pressure, pulse rate, body temperature and the number of steps together with relation between standard deviation of measured physical conditions of blood pressure, pulse rate, body temperature and the number of steps and physical and psychological stress for the male whose age is 36 years old

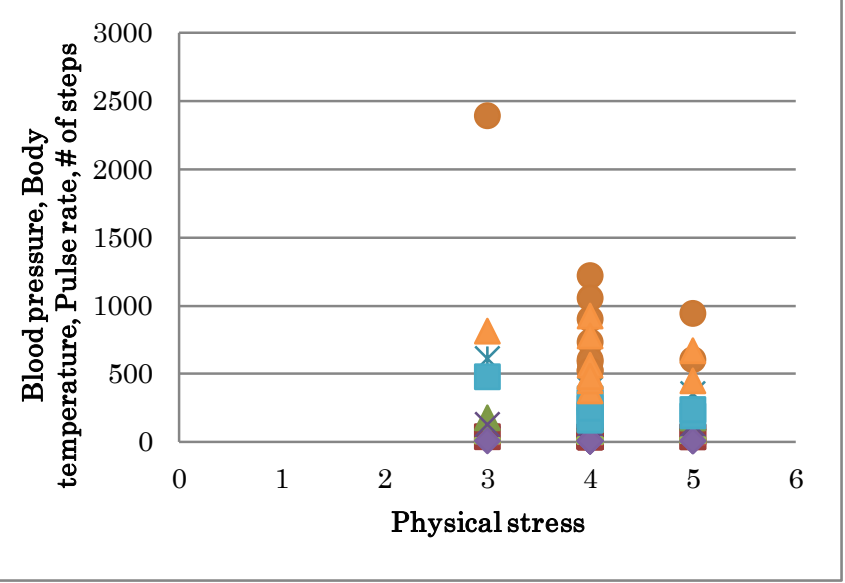

(a)Mean of physical condition (Physical stress)

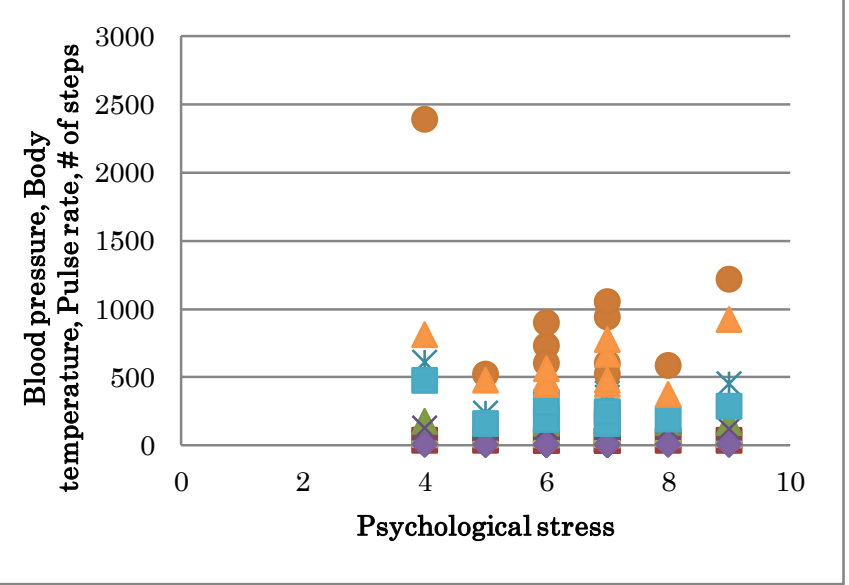

(b) Mean of physical condition (Psychological stress)

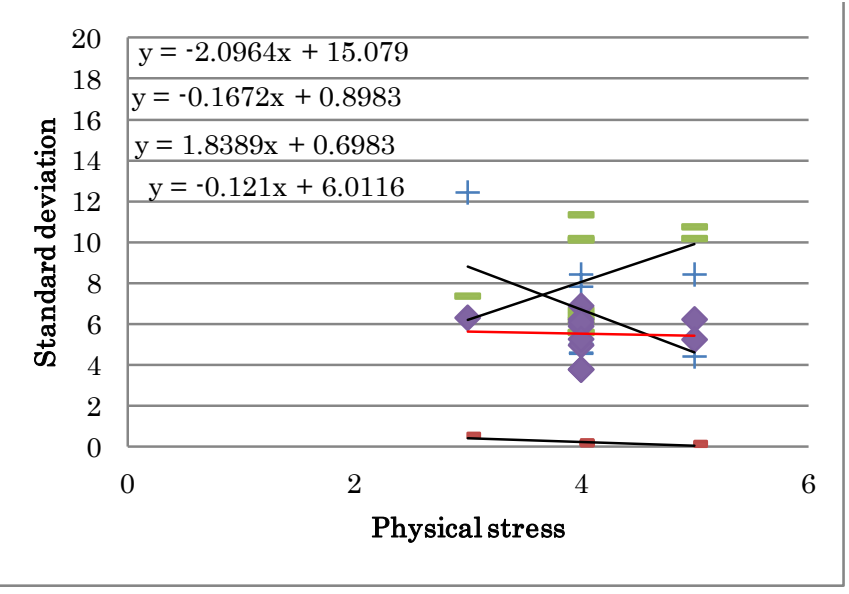

(c) Standard deviation of physical condition (Physical stress) 


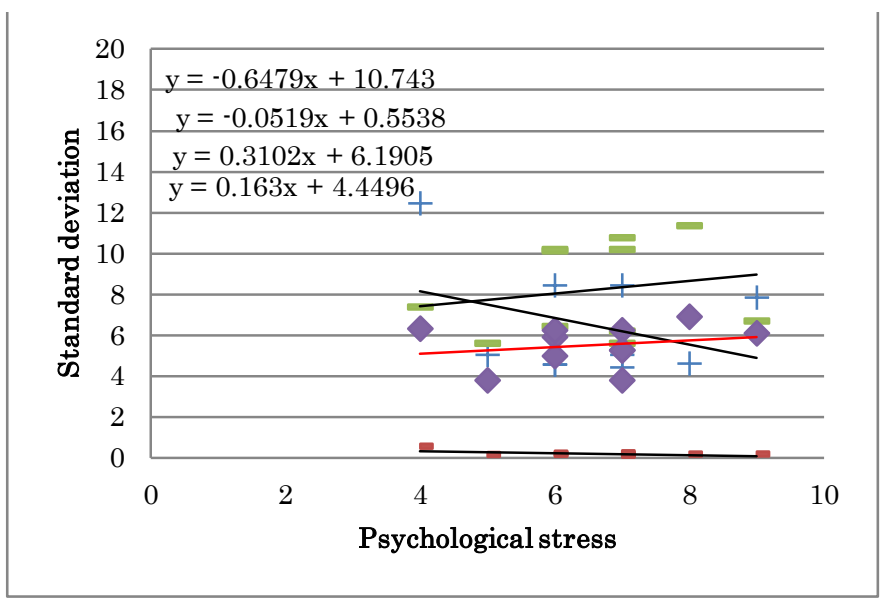

(d)Standard deviation of physical condition (Psychological stress)

Fig. 8. Relation between physical stress as well as psychological stress and measured physical conditions of blood pressure, pulse rate, body temperature and the number of steps together with relation between standard deviation of measured physical conditions of blood pressure, pulse rate, body temperature and the number of steps and physical and psychological stress for the male whose age is 49 years old

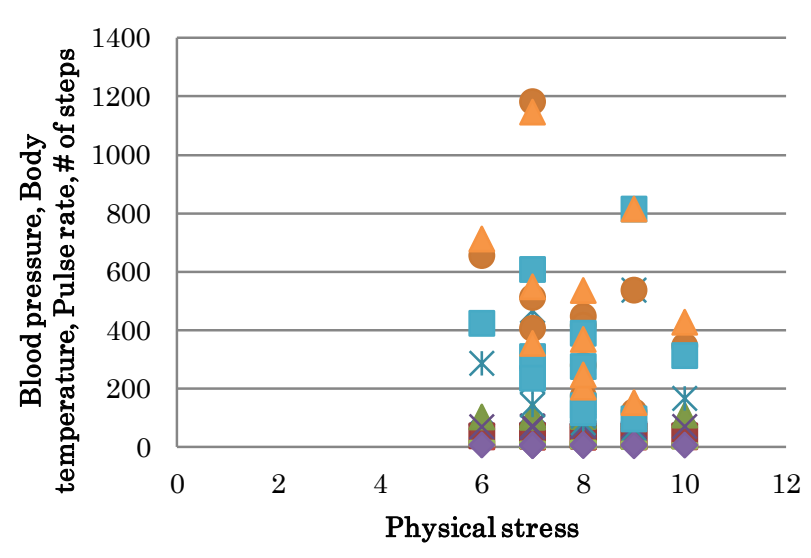

(a)Mean of physical condition (Physical stress)

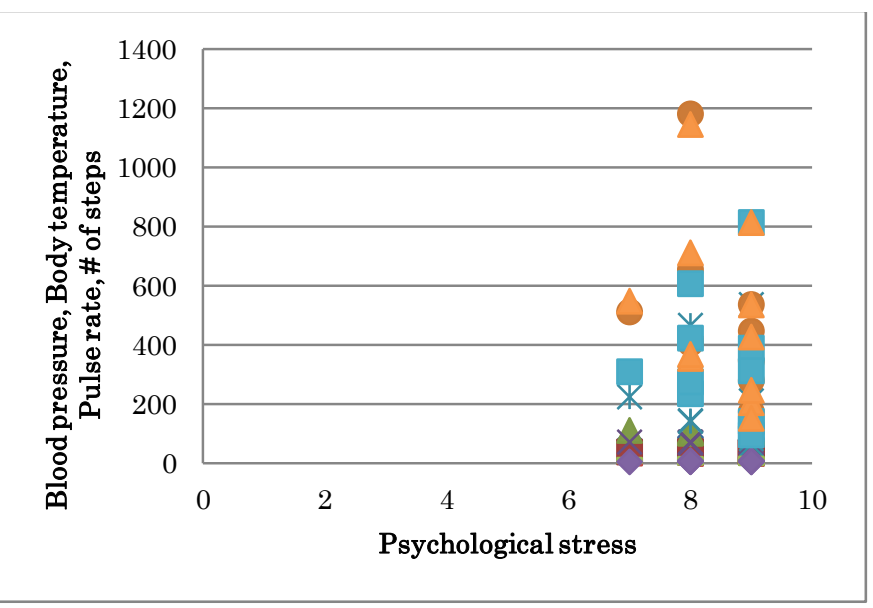

(b) Mean of physical condition (Psychological stress)

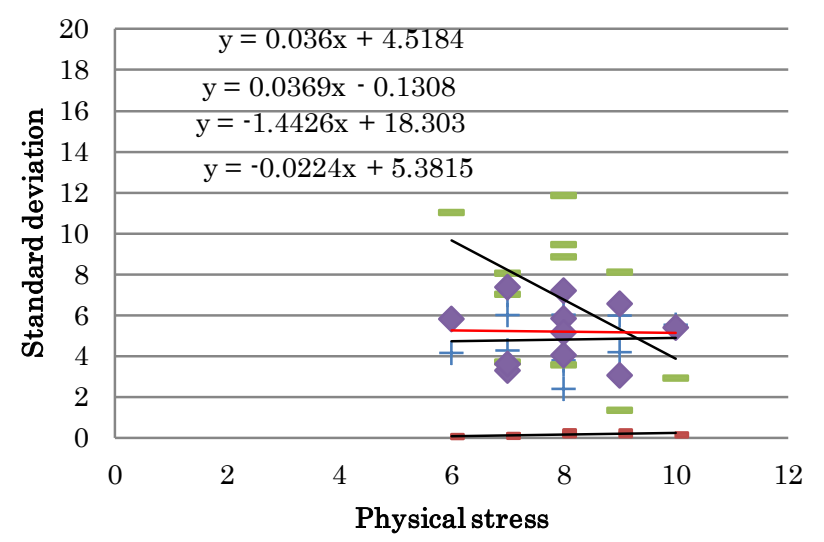

(c) Standard deviation of physical condition (Physical stress)

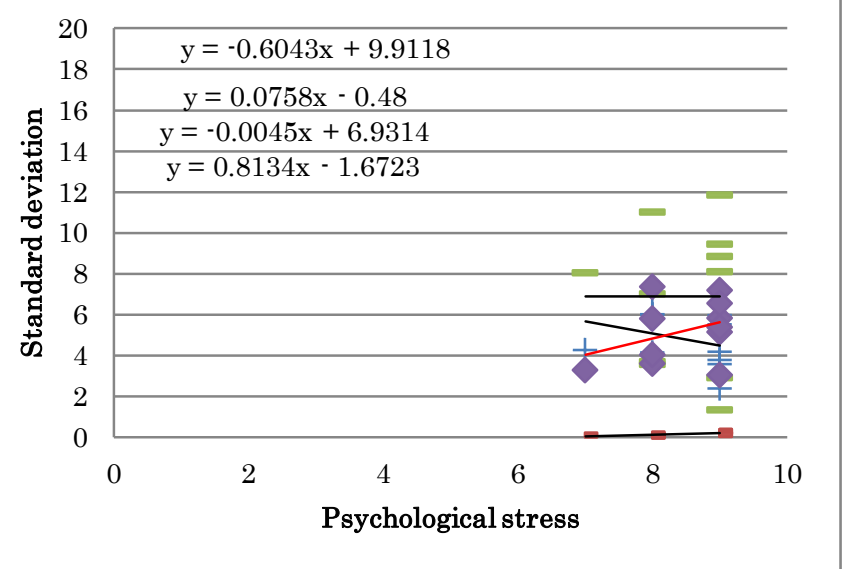

(d)Standard deviation of physical condition (Psychological stress)

Fig. 9. Relation between physical stress as well as psychological stress and measured physical conditions of blood pressure, pulse rate, body temperature and the number of steps together with relation between standard deviation of measured physical conditions of blood pressure, pulse rate, body temperature and the number of steps and physical and psychological stress for the female whose age is 58 years old

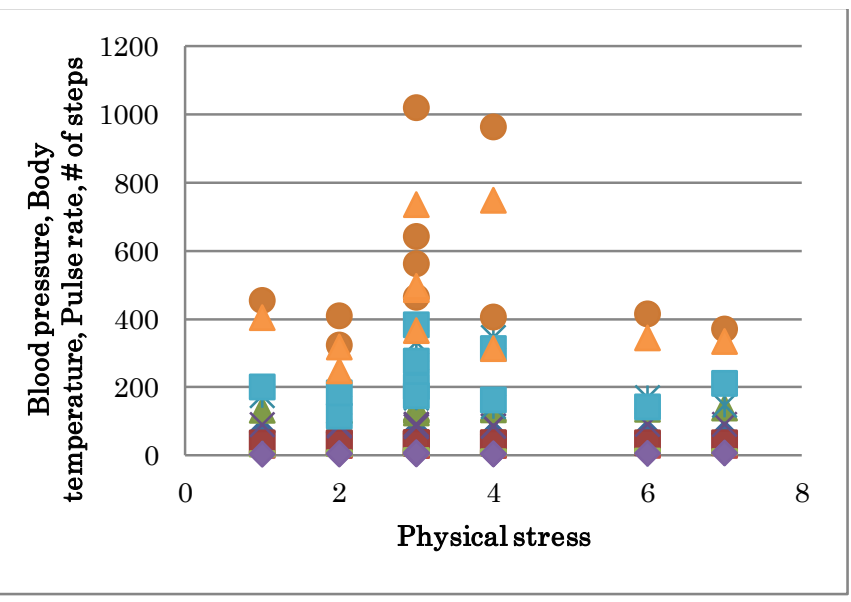

(a)Mean of physical condition (Physical stress) 


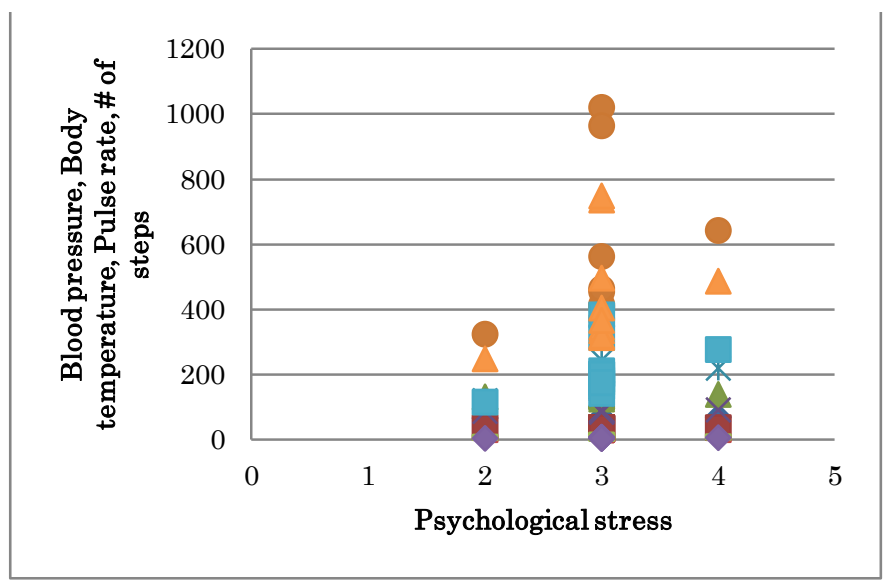

(b) Mean of physical condition (Psychological stress)

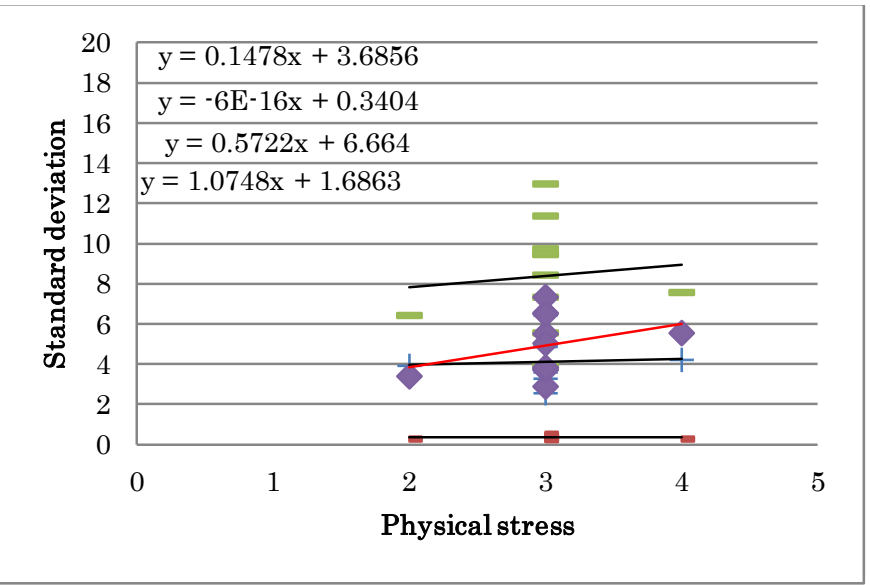

(c) Standard deviation of physical condition (Physical stress)

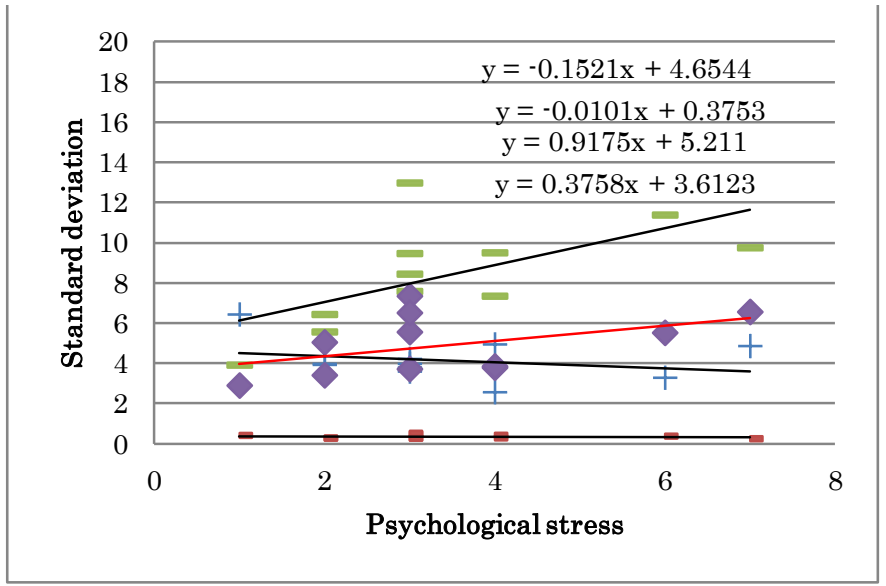

(d)Standard deviation of physical condition (Psychological stress)

Fig. 10. Relation between physical stress as well as psychological stress and measured physical conditions of blood pressure, pulse rate, body temperature and the number of steps together with relation between standard deviation of measured physical conditions of blood pressure, pulse rate, body temperature and the number of steps and physical and psychological stress for the female whose age is 56 years old

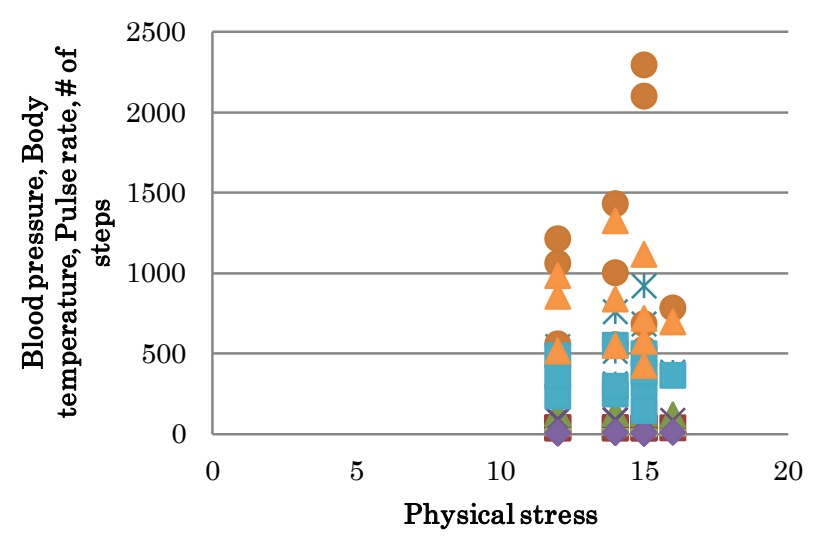

(a)Mean of physical condition (Physical stress)

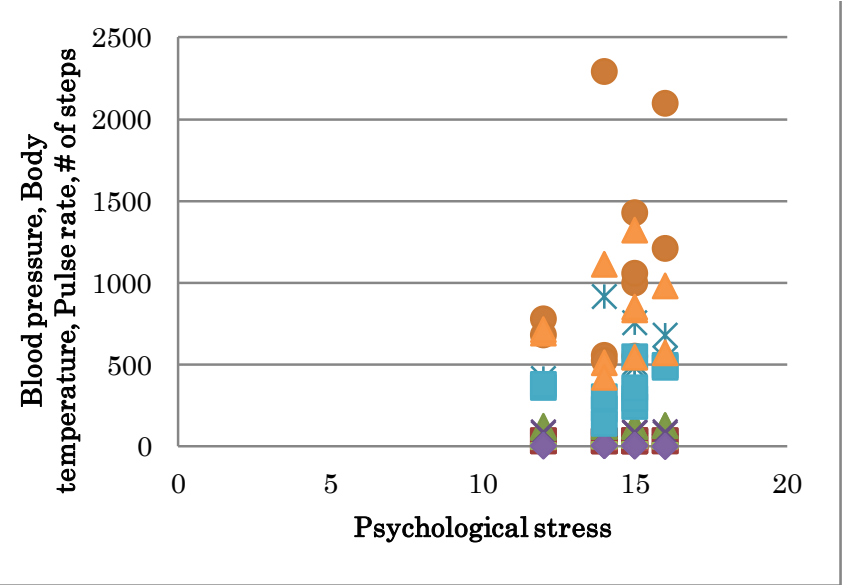

(b) Mean of physical condition (Psychological stress)

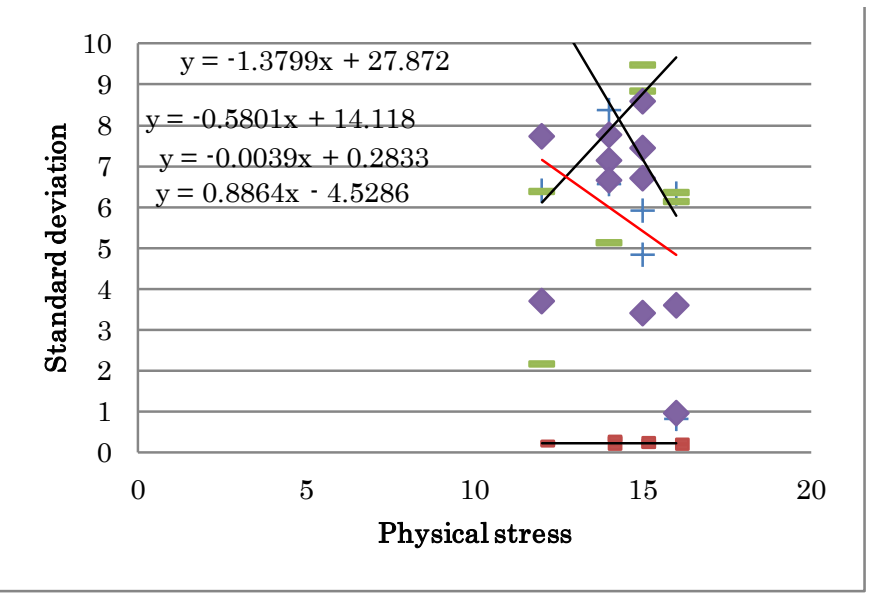

(c) Standard deviation of physical condition (Physical stress) 


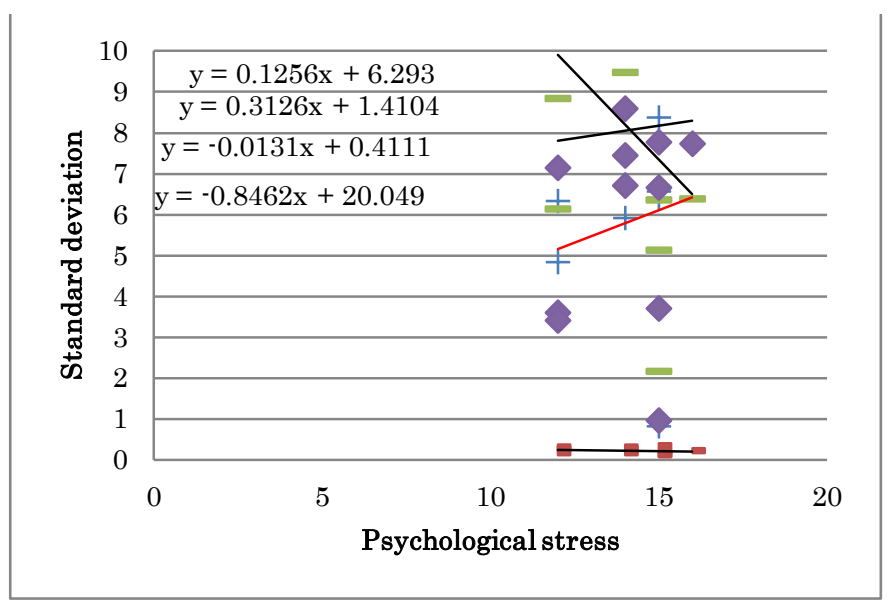

(d)Standard deviation of physical condition (Psychological stress)

Fig. 11. Relation between physical stress as well as psychological stress and measured physical conditions of blood pressure, pulse rate, body temperature and the number of steps together with relation between standard deviation of measured physical conditions of blood pressure, pulse rate, body temperature and the number of steps and physical and psychological stress for the male whose age is 39 years old

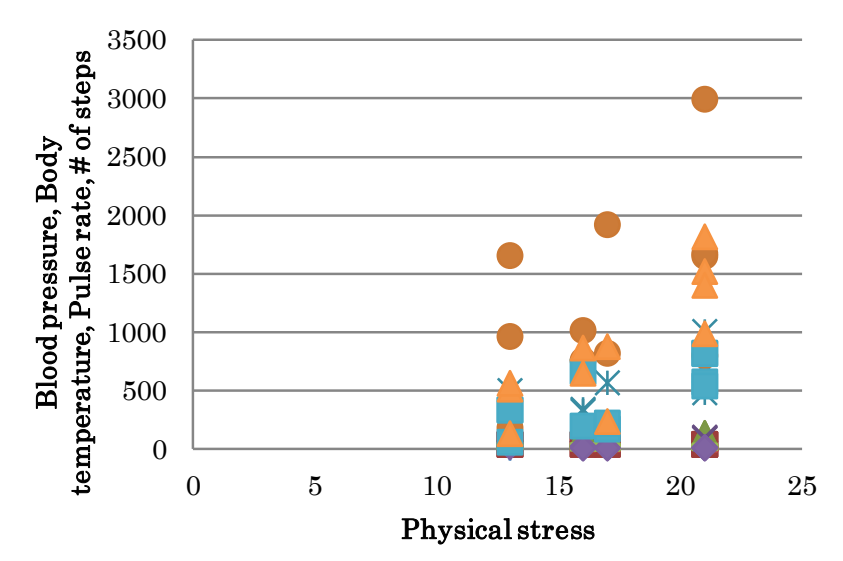

(a)Mean of physical condition (Physical stress)

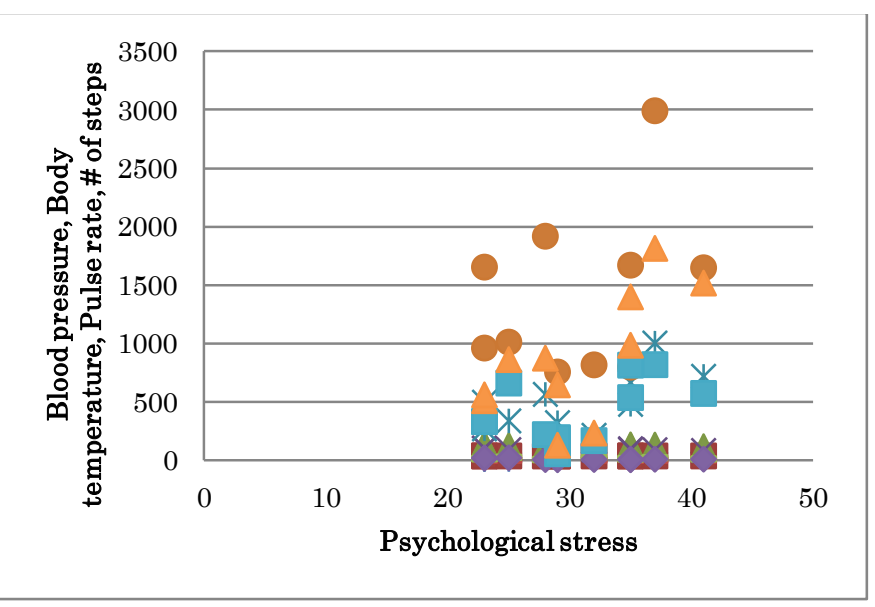

(b) Mean of physical condition (Psychological stress)

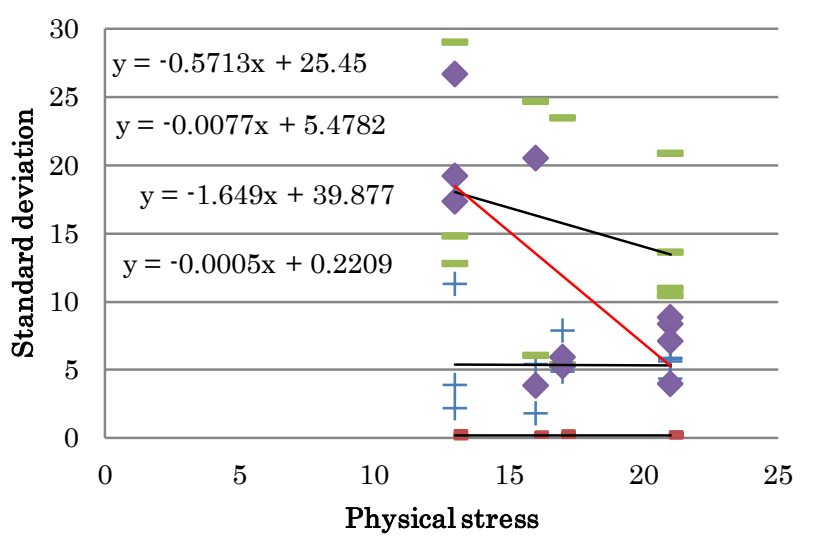

(c) Standard deviation of physical condition (Physical stress)

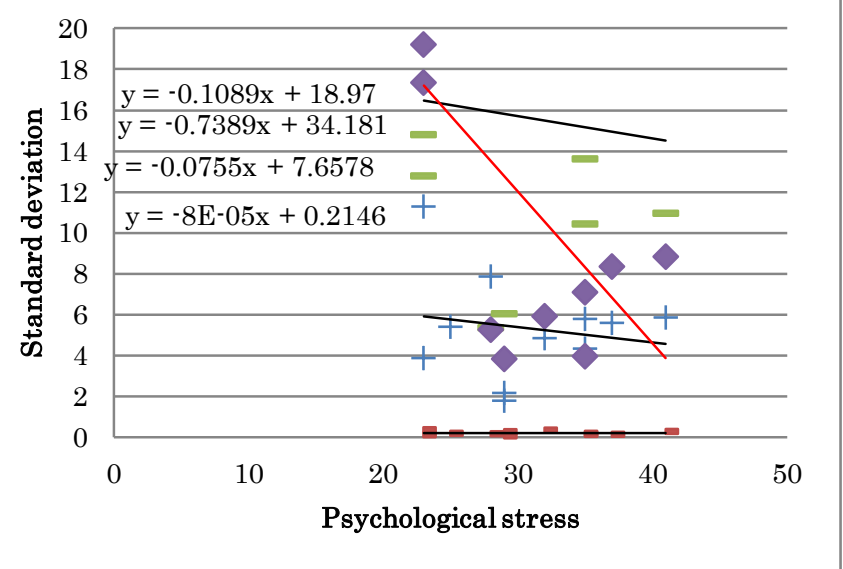

(d)Standard deviation of physical condition (Psychological stress)

Fig. 12. Relation between physical stress as well as psychological stress and measured physical conditions of blood pressure, pulse rate, body temperature and the number of steps together with relation between standard deviation of measured physical conditions of blood pressure, pulse rate, body temperature and the number of steps and physical and psychological stress for the female whose age is 53 years old

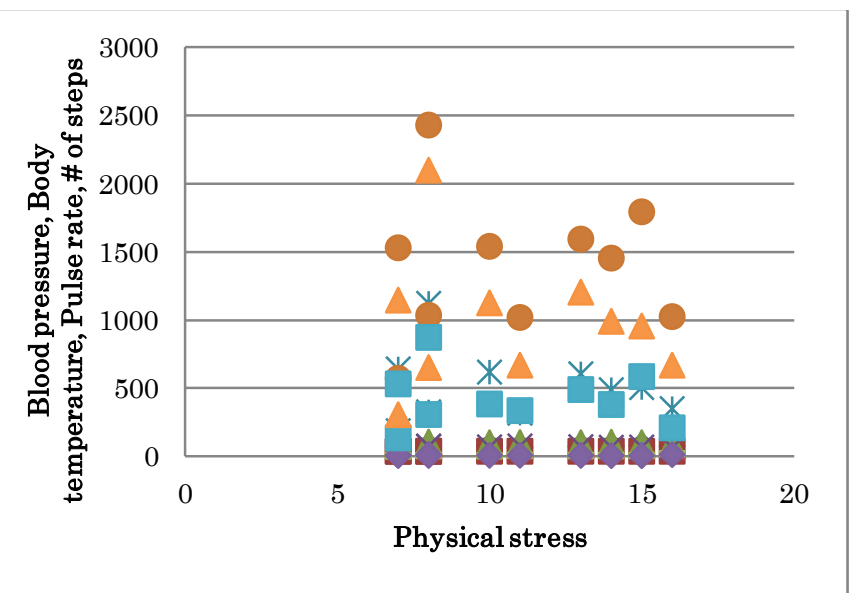

(a)Mean of physical condition (Physical stress) 


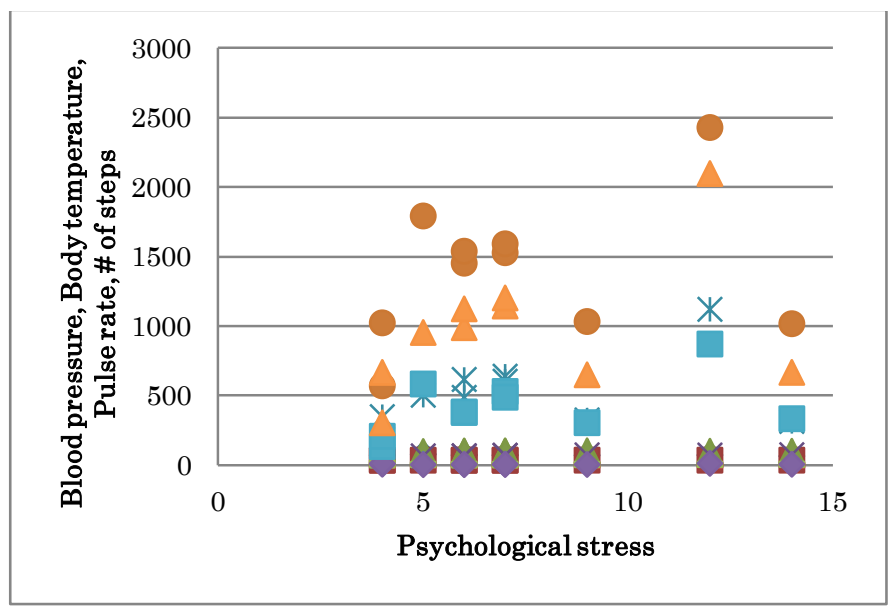

(b) Mean of physical condition (Psychological stress)

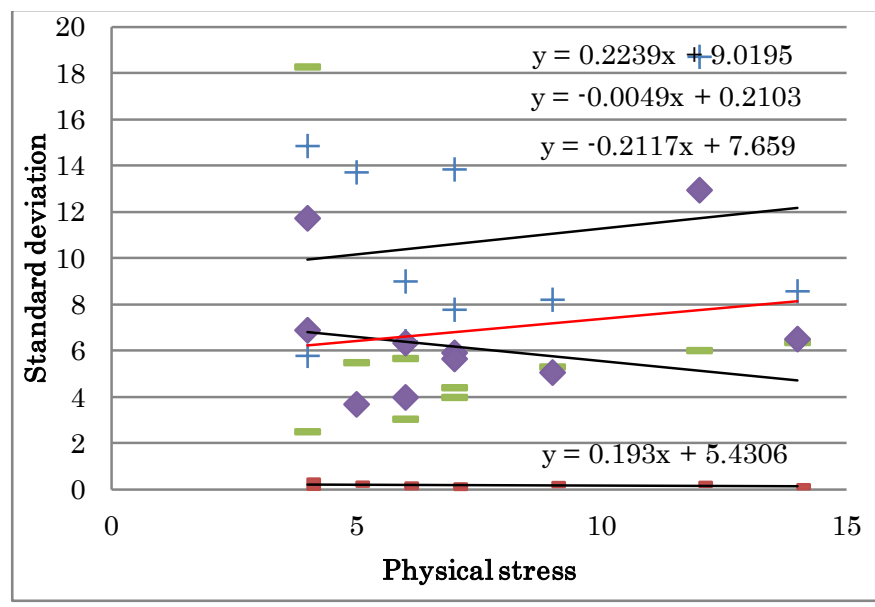

(c) Standard deviation of physical condition (Physical stress)

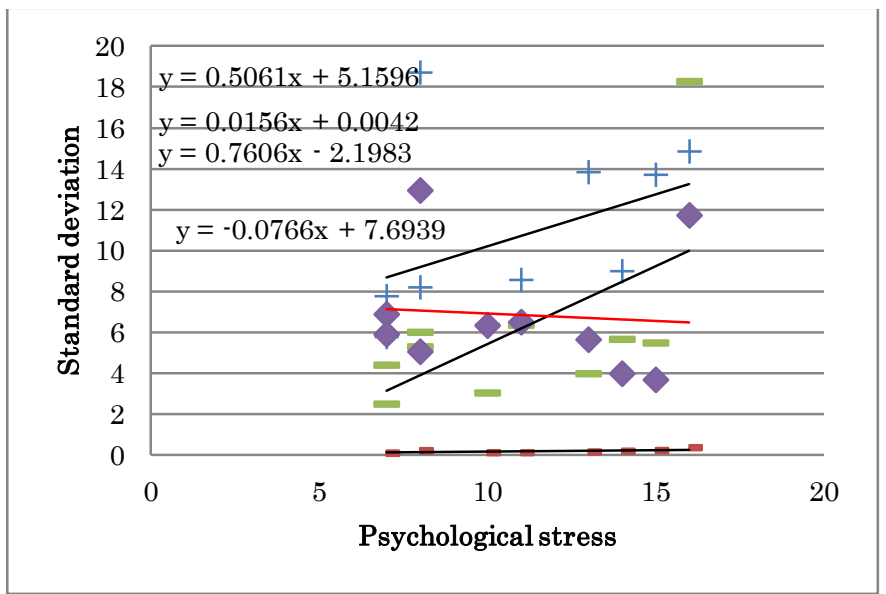

(d)Standard deviation of physical condition (Psychological stress)

Fig. 13. Relation between physical stress as well as psychological stress and measured physical conditions of blood pressure, pulse rate, body temperature and the number of steps together with relation between standard deviation of measured physical conditions of blood pressure, pulse rate, body temperature and the number of steps and physical and psychological stress for the female whose age is 29 years old
Through these experiments, it is found that the followings,

- There is no difference between male and female on physical and psychological stress

- There is difference between the person in healthy condition and the patient with weak Alzheimer

- There are age dependencies on physical and psychological stress as well as blood pressure

- In accordance with increasing of the number of steps, physical stress is increased while psychological stress is decreased. This trend is observed from the relations between standard deviation of physical conditions, blood pressure, body temperature, pulse rate and physical and psychological stress. Also this trend is remarkable for young generation of patients.

Consciousness is measured with EEG sensor together with eye movement observation. Quick eye movements (Succored movements) are highly related to EEG sensor signals. This fact is verified with the following experiments.

By using EEG analyzer tools, we analyze the fatigue effect between the condition when user is looking at one point and condition when user is looking at four points. In order to analyze fatigue effect, we use Peak Alpha Frequency: PAF [8]-[11]. It is possible to measure psychological status by using PAF derived from EEG signal. Psychological health condition is measured with Bio Switch MCTOS of Brain Wave Measuring instrument (BM-Set1) manufactured by Technos Japan Co. Ltd. every one hour.

Figure 14 shows alpha and beta frequency components of EEG signals measured with the male patient whose age is 49 . At the begging of the experiment, he surprised so much that beta signal raised remarkably. At that time, his eye moved as quickly as shown in Figure 15. This situation is same for the other patients. Therefore, it is said that there is high relation between eye movement and psychological status.

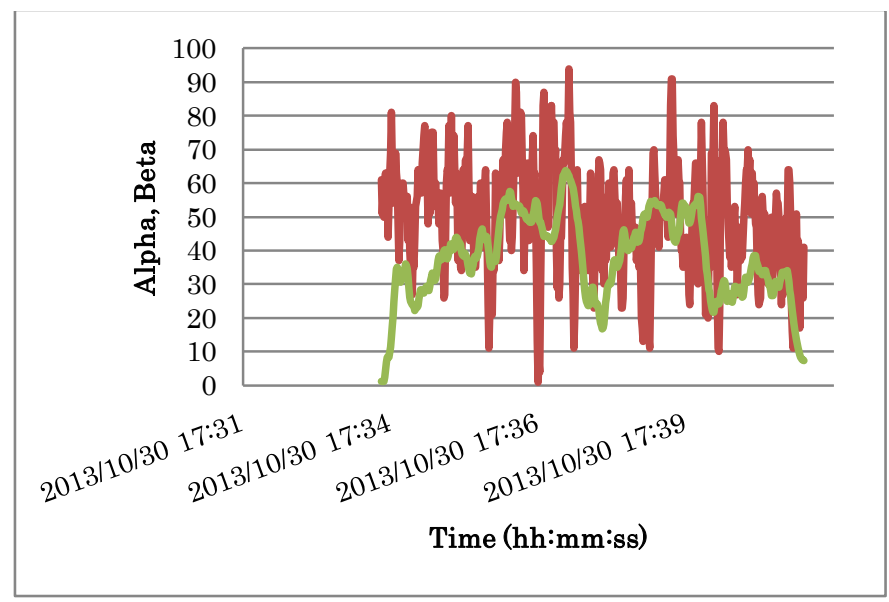

Fig. 14. alpha and beta frequency components of EEG signals measured with the male patient whose age is 49 


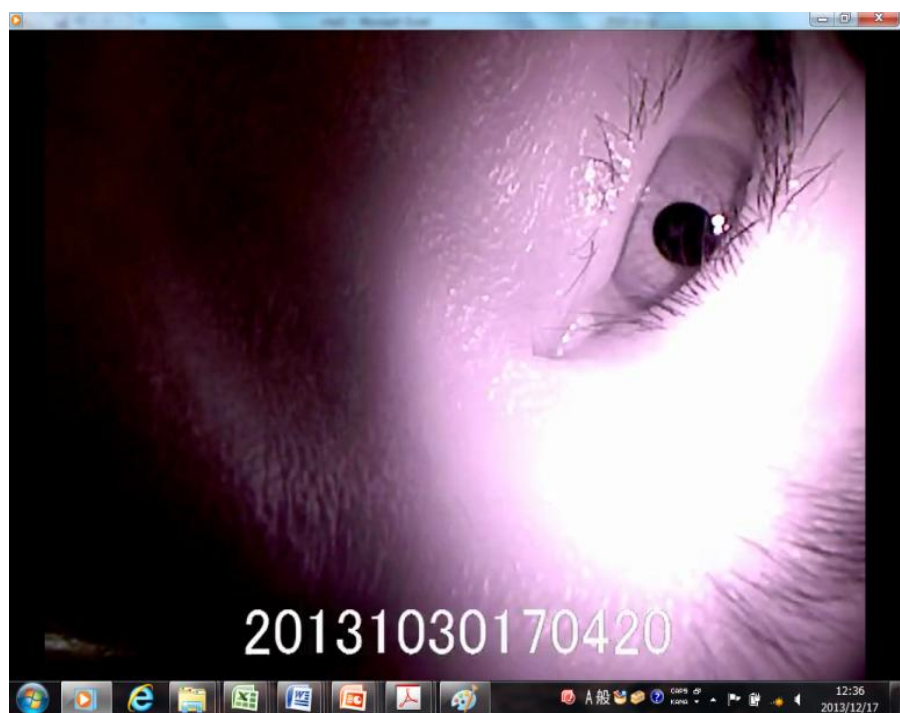

Fig. 15. Quick eye movements observed for the male patient whose age is 49

\section{CONCLUSION}

Method and system for vital sign (Body temperature, blood pressure, bless, Heart beat pulse rate, and consciousness) and location/attitude monitoring with sensor network for the proposed rescue system for disabled and elderly persons who need a help in evacuation from disaster areas is proposed. Experimental results show that all of vital signs as well as location and attitude of the disabled and elderly persons are monitored with the proposed sensor networks.

Through the experiments with 11 patients, it is found the followings,

- There is no relation between pulse rate and age

- Body temperature is stable for time duration through the experiments

- There is no age dependency on the number of steps (calorie consumption)

- Psychological status can be estimated with eye movements $\rightarrow$ There is relation between EEG signal and eye movements (psychological status)

- There is no difference between male and female on physical and psychological stress

- There is difference between the person in healthy condition and the patient with weak Alzheimer

- There are age dependencies on physical and psychological stress as well as blood pressure
- In accordance with increasing of the number of steps, physical stress is increased while psychological stress is decreased. This trend is observed from the relations between standard deviation of physical conditions, blood pressure, body temperature, pulse rate and physical and psychological stress. Also this trend is remarkable for young generation of patients.

\section{ACKNOWLEDGMENT}

The author would like to thank all the patients who are contributed to the experiments conducted. The author also would like to thank Professor Dr. Takao Hotokebuchi, President of Saga University for his support this research works.

\section{REFERENCES}

[1] Kohei Arai, Tran Xuan Sang, Decision making and emergency communication system in rescue simulation for people with disabilities, International Journal of Advanced Research in Artificial Intelligence, 2, 3, 77-85, 2013.

[2] K.Arai, T.X.Sang, N.T.Uyen, Task allocation model for rescue disable persons in disaster area with help of volunteers, International Journal of Advanced Computer Science and Applications, 3, 7, 96-101, 2012.

[3] K.Arai, T.X.Sang, Emergency rescue simulation for disabled persons with help from volunteers, International Journal of Research and Review on Computer Science, 3, 2, 1543-1547, 2012.

[4] K. Arai, and T. X. Sang, "Fuzzy Genetic Algorithm for Prioritization Determination with Technique for Order Preference by Similarity to Ideal Solution", International Journal of Computer Science and Network Security, vol.11, no.5, 229-235, May 2011.

[5] Arai K., R. Mardiyanto, Evaluation of Students' Impact for Using the Proposed Eye Based HCI with Moving and Fixed Keyboard by Using EEG Signals, International Journal of Review and Research on Computer Science(IJRRCS), 2, 6, 1228-1234, 2011

[6] K.Arai, Wearable healthy monitoring sensor network and its application to evacuation and rescue information server system for disabled and elderly person, International Journal of Research and Review on Computer Science, 3, 3, 1633-1639, 2012.

[7] K.Arai, Wearable Physical and Psychological Health Monitoring System, Proceedings of the Science and Information Conference 2013 October 79, 2013 | London, UK

\section{AUTHORS PROFILE}

Kohei Arai, He received BS, MS and PhD degrees in 1972, 1974 and 1982, respectively. He was with The Institute for Industrial Science and Technology of the University of Tokyo from April 1974 to December 1978 also was with National Space Development Agency of Japan from January, 1979 to March, 1990. During from 1985 to 1987, he was with Canada Centre for Remote Sensing as a Post Doctoral Fellow of National Science and Engineering Research Council of Canada. He moved to Saga University as a Professor in Department of Information Science on April 1990. He was a councilor for the Aeronautics and Space related to the Technology Committee of the Ministry of Science and Technology during from 1998 to 2000. He was a councilor of Saga University for 2002 and 2003. He also was an executive councilor for the Remote Sensing Society of Japan for 2003 to 2005. He is an Adjunct Professor of University of Arizona, USA since 1998. He also is Vice Chairman of the Commission "A" of ICSU/COSPAR since 2008. He wrote 31 books and published 442 journal papers 